\title{
Bone density estimates and risk factors for osteoporosis in young women
}

\author{
H.F. Saadi, ${ }^{1}$ R.L. Reed, ${ }^{2}$ A.O. Carter, ${ }^{3}$ H.S. Qazaq ${ }^{4}$ and A.R. Al-Suhail ${ }^{5}$
}

$$
\begin{aligned}
& \text { التقدير ات المتعلقة بكدافة العظام وعوأمل انحتطار تخلنحل العظام في صفرف الثبابات }
\end{aligned}
$$

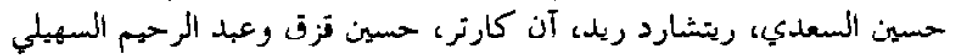

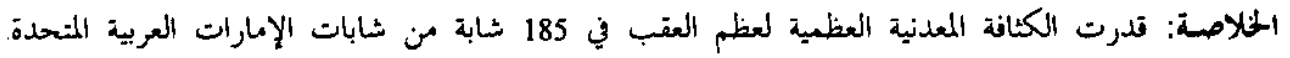

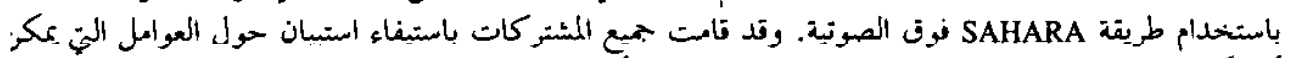

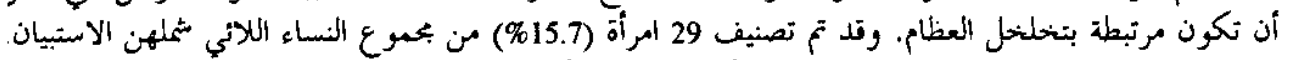

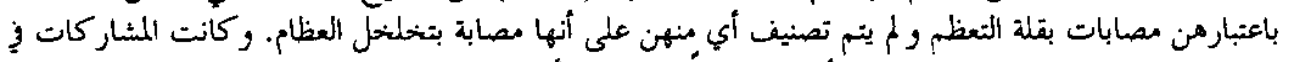

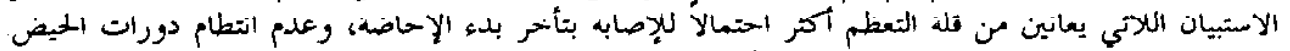

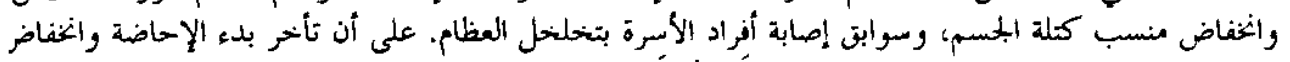

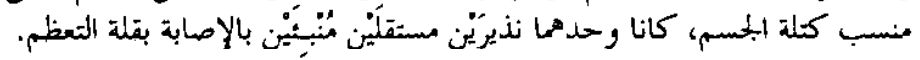

ABSTRACT The bone mineral density (BMD) of the calcaneus was estimated in 185 young women from the United Arab Emirates, using SAHARA ultrasound. All participants completed a questionnaire on factors potentially associated with osteoporosis. In all, $29(15.7 \%)$ of the women were classified as having osteopenia and none as having osteoporosis. Participants with osteopenia were more likely to have had a later onsei of menarche, irregular periods, lower body mass index, and a positive family history of osteoporosis. Only late menarche and low body mass index, however, were independent predictors of osteopenia.

\section{Estimations de la densité osseuse et facteurs de risque d'ostéoporose chez les jeunes femmes}

RESUME On a estimé la densité minérale du calcanéum chez 185 jeunes femmes des Emirats arabes unis, en utilisant les ultrasons SAHARA. Toutes les participantes ont rempli un questionnaire sur les facteurs potentiellement associés à l'ostéoporose. En tout, on a classé $29(15,7 \%)$ des femmes comme ayant une ostéopénie et aucune comme ayant une ostéoporose. Les participantes atteintes d'ostéopénie connaissaient davantage de probabilités d'avoir une menstruation tardive, des irrégularités menstruelles, un indice de masse corporelte inférieur et des antécédents familiaux positifs d'ostéoporose. Toutefois, seuls les menstruations tardives et le faible indice de masse corporelle étaient des facteurs prédictifs indépendants d'ostéopénie.

'Department of internal Medicine; ${ }^{2}$ Department of Family Medicine; ${ }^{3}$ Department of Community Medicine. Faculty of Medicine and Health Sciences. United Arab Emirates University. United Arah Emirates.

${ }^{4}$ Department of Nutrition, Al-Ain Medical District, Ministry of Health, United Arab Emirates.

${ }^{5}$ Department of Nuclear Medicine, Tawam Hospital, Ministry of Health, United Arab Emirates.

Rocoivod: 03/09/00; accoptod: 05/12/00 


\section{Introduction}

The attainment of a higher peak bone density has an important role in the prevention of osteoporosis later in life [1-3]. Genetic factors and race/ethnicity have a strong influence on peak bone density [4-6]. Physiological, environmental, and modifiable lifestyle factors can also play a significant role $[5,7]$. These factors include adequate nutrition and body weight [8,9], exposure to sex hormones at puberty $[10,11]$ and level of physical activity $[12,13]$, and are not only important for the acquisition of maximal bone mass but also for its maintenance throughout life $[5,14-16]$. The primary objective of this study was to determine the corrclation between bone mineral density (BMD) and potential risk factors for osteoporosis in a population of young healthy United Arab Emirates (UAE) women. A second objective was to compare the BMD of UAE women with that of other ethnic groups.

\section{Methods}

\section{Paticipants}

Two hundred young UAE female nationals were invited by local advertisement and site visits to participate in this cross-sectional study. Of those enrolled, $84(42 \%)$ were medical students, $82(41 \%)$ college and university students, $20(10 \%)$ members of a women's social club and $14(7 \%) \mathrm{em}$ ployees of a health department; 15 women with a history of chronic illnesses and/or use of thyroid or glucocorticoid medications were excluded from the analysis. Ethical approval was obtained from the Ethics Committee of the Faculty of Medicine and Health Sciences, United Arab Emirates University.

\section{Questionnaire}

After giving informed consent, each participant filled out a questionnaire in Arabic or English on factors thought to be associated with osteoporosis, such as reproductive history, dietary calcium intake, physical activity, exposure to sun, tobacco use, alcohol consumption, and family history of osteoporosis. Estimation of dietary calcium was based on a quantitative food frequency questionnaire in Arabic adapted to the local dietary customs. The questionnaire included local food items contributing significantly to calcium intake. Dietary calcium intake (g/day) was calculated from the participants' answers to the food frequency questionnaire using tables that define the calcium content of local foods [17]. Skin exposure to sunlight was determined from the participant's reported length of time (minutes/day) spent in the courtyard of her house. In this cultural group, this is where most exposure to sunlight occurs because in all other outdoor situations women generally wear dark clothes including head coverings and, in many cases, veils. Physical activity level was estimated from the answers to four questions related to exercise. These questions asked whether the participants walked carrying a load at least once per day, or walked for exercise, climbed stairs, or performed any other exercise activity at least ouce per week. Participants were defined as sedentary if they answered yes to one or fewer questions, mildly active if they answered yes to two questions, and moderately active if they answered yes to three to four questions.

\section{Measurement of bone density}

BMD $\left(\mathrm{g} / \mathrm{cm}^{2}\right)$ of the right calcaneus was estimated in all participants using a SAIIARA ultrasound bone densitometer (Hologic, Waltham, United States of America), which

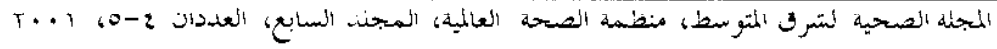


measures the transmission of high frequency sound waves through the heel. From the measured signal, three ultrasound parameters are simultaneously determined: speed of sound (SOS), broadband ultrasound attenuation (BUA) and the quantitative ultrasound index (QUI). The SAHARA system software estimates BMD from the QUI and compares it to that of young, healthy, sex matched subjects to produce a T-score. The T-score is widely used to assist in the interpretation of BMD results. It measures the departure of the person's BMD value from the mean BMD for a young adult population in units of the population standard deviation. Estimated BMD measurements of the calcaneus for young healthy UAE women were compared with the manufacturer's reference for US Caucasian, European Caucasian and Chinese Asian young healthy women of the same age range [18]. In addition, dual-energy $X$-ray absorptiometry (DXA) scans (Lunar Expert XL, Madison, United States of America) of the lumbar spine and femurs were performed in 10 participants. Height in centimetres and weight in kilograms were also measured in all participants.

\section{Statistical analysis}

Data were processed using $S P S S$, version 10.0. Data were expressed as the mean and standard deviation (SD) unless otherwise stated. Bivariate analysis was performed using a $t$-test for continuous variables and chi-squared analysis for discontinuous variables. Subsequently, stepwise logistic regression was performed to determine a multivariate summary model of risk factors for the development of low BMD. Using clinically derived cut-off points for analy. sis, potential risk factors were assessed using chi-squared odds ratios. The subsequent analysis strategy involved the initial selection of all dichotomous variables whose associated chi-squared statistics had $P$-values below 0.05 . Stepwise regression was performed using forward selection, with a $P$-value of 0.10 for entry and 0.20 for removal. The final model included only those risk factors whose unique contribution, in the presence of all other variables, was significant at a level of alpha $=$ 0.05 .

\section{Results}

A total of 185 young healthy UAE women participated in the study. The median age was 22 years (range 18-36 years). Mean age at menarche was $13.1 \pm 1.26$ years, and mean BMI was $24.9 \pm 5.0 \mathrm{~kg} / \mathrm{m}^{2}$. Only a few participants were taking calcium or vitamin D supplements (3.3\%), multivitamins $(11.9 \%)$, or had had previous BMD measurement $(3.3 \%)$. None of the participants smoked cigarettes or consumed alcohol. Mean dietary calcium intake was 968.4 $\pm 707.6 \mathrm{mg} /$ day and 44 participants $(23.8 \%)$ consumed less than $500 \mathrm{mg}$ calcium per day. Table 1 shows exercise, exposure to sunlight, reproductive history and family history of osteoporosis of the study participants.

The estimated mean BMD was $0.56 \pm$ $0.13 \mathrm{~g} / \mathrm{cm}^{2}$. The frequency of distribution of estimated BMD values is shown in Figure 1. The distribution is approximately normal (skewness $=0.440$, standard error of the mean $=0.179 ;$ kurtosis $=-0.171$, standard error of the mean $=0.355$ ). Using the World Health Organization criteria and the mean BMD value of $0.56 \pm 0.13 \mathrm{~g} / \mathrm{cm}^{2}$ as a reference, $29(15.7 \%)$ participants were classified as having osteopenia ( $\mathrm{T}$ score between -1 and -2.4 , or BMD $<0.43$ $\mathrm{g} / \mathrm{cm}^{2}$ ) and none as having osteoporosis ( $\mathrm{T}$ score $\leq-2.5$ ). When reference data for American Caucasian women (mean age 25 years) were used, however, $50(27 \%)$ and 
Table 1 Exercise, exposure to sunlight, reproductive history and family history of osteoporosis in study parlicipants

\begin{tabular}{lcc}
\hline Category a & No. & $\%$ \\
\hline Exercise status & 19 & 10.3 \\
$\quad$ Sedentary & 57 & 30.8 \\
$\quad$ Mildly active & 87 & 47.0 \\
$\quad$ Moderately active & 22 & 11.9 \\
$\quad$ Missing & & \\
Exposure to & \\
sunlight (mirutes/day) & & \\
$<30$ & 55 & 29.7 \\
30-60 & 69 & 37.3 \\
>60 & 61 & 33.0 \\
Reproductive history & & \\
Irregular menstrual & & \\
periods \\
Late menarche & 36 & 19.5 \\
(onset > 15 years) & 27 & 14.6 \\
$\quad \begin{array}{l}\text { Parity } \\
\text { History of oral } \\
\text { contraceptive use }\end{array}$ & 29 & 15.7 \\
Family history of & 23 & 12.4 \\
$\quad$ osteoporosis & & \\
\hline
\end{tabular}

$2(1.1 \%)$ of study subjects were classified as having osteopenia and osteoporosis respectively. Table 2 shows the characteristics of the participants according to their BMD category: normal mean BMD of 0.59 $\pm 0.11 \mathrm{~g} / \mathrm{cm}^{2}$ versus osteopenic mean BMD of $0.38 \pm 0.04 \mathrm{~g} / \mathrm{cm}^{2}$. Participants with osteopenia were more likely to have had a later onset of menarche $(P=0.011)$, irregular periods $(P=0.077)$, lower BMI $(P=$ $0.037)$ and positive family history of osteoporosis $(P=0.053)$ than those with normal BMD. When these four risk factors were entered into a stepwise multiple logistic regression analysis model, only iate menarche and low BMI were independent predictors of osteopenia (odds ratio $=2.99$, $95 \%$ confidence interval: $1.08-8.30$ and odds ratio $=1.15,95 \%$ confidence interval: 1.03-1.29 respectively) (Table 3 ). The correlation berween calcaneus BMD measured by SAHARA ultrasound and hip BMD measured by Lunar DXA was determined in 10 paricipants. The correlation coefficient

For definition of categories see text.

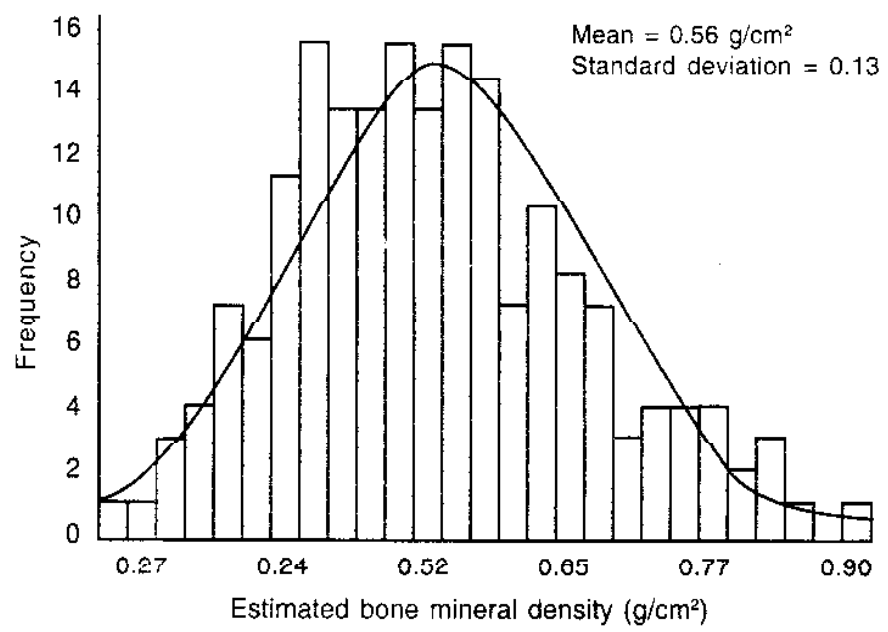

Figure 1 Frequeney of bone mineral density distribution in the 105 participants 
Table 2 Characteristics of the study participants according to bone mineral density (BMD) category

\begin{tabular}{lcc} 
Characteristic & $\begin{array}{c}\text { Participants with } \\
\text { normal BMD }(n=156)\end{array}$ & $\begin{array}{c}\text { Participants } \\
\text { with osteopenia }(n=29)\end{array}$ \\
\hline Age $\pm s$ (years) & $22.7 \pm 3.0$ & $22.0 \pm 4.5$ \\
Body mass index $\pm s\left(\mathrm{~kg} / \mathrm{m}^{2}\right)$ & $25.2 \pm 5.0$ & $23.1 \pm 4.1^{*}$ \\
Calcium intake $\pm s(\mathrm{mg} /$ day) & $976.3 \pm 755.4$ & $703.2 \pm 352.4$ \\
Exposure to sunlight $\pm s($ minutes/day) & $55.8 \pm 47.6$ & $65.5 \pm 52.0$ \\
Exercise (\% sedentary) & 11.3 & 15.4 \\
Age at menarche $=s$ (yoars) & $13.0 \pm 1.2$ & $13.7 \pm 1.4^{*}$ \\
Late menarche $(\%)$ & 13.5 & $29.6^{*}$ \\
Irregular menstrual periods (\%) & 17.6 & 32.1 \\
Parity (\%) & 13.5 & 13.8 \\
Oral contraceptive use (\%) & 13.2 & 16.0 \\
Family history of osteoporosis $(\%)$ & 11.0 & 24.1 \\
\hline
\end{tabular}

*Significant at $P<0.05$.

$\mathrm{s}=$ standard deviation.

was statistically significant $(r=0.7, P<$ $0.05)$.

\section{Discussion}

The distribution of estimated BMD values in this group of 185 young healthy UAE women was approximately normal. Hence, the mean BMD value could be compared with mean BMD values of healthy young women from different ethnic groups using the same ultrasound technology (Figure 2). Although UAE participants had the lowest mean BMD, the differences between UAE and United States Caucasian women and Chinese women were not statistically significant $(P=0.09$ and 0.63 respectively). Hence the differences in fracture rates among these populations, if any, will more likely be determined by differences in the magnitude of bone loss that occurs after achieving peak bone mass.
Factors that are important in maintaining bone mass include adequate nutrition and body weight, exposure to sex hormones and physical activity $[5,14-16]$. In this study, participants with osteopenia were more likely to have a later onset of menarche, irregular menstrual periods, lower BMI and positive family history of osteoporosis than those with normal BMD. Only late menarche and low BMI, however, were independently predictive of osteope-

Table 3 Multiple logistic regression analysis model for osteopenia risk factors

\begin{tabular}{lccc}
\hline RIsk factor & $\begin{array}{c}\text { Oads } \\
\text { ratio }\end{array}$ & $\begin{array}{c}\mathbf{9 5 \%} \\
\text { confidence } \\
\text { interval }\end{array}$ & P-value \\
\hline $\begin{array}{l}\text { Late menarche } \\
\begin{array}{l}\text { Low body } \\
\text { mass index }\end{array}\end{array}$ & 2.99 & $1.08-8.30$ & 0.035 \\
\hline
\end{tabular}




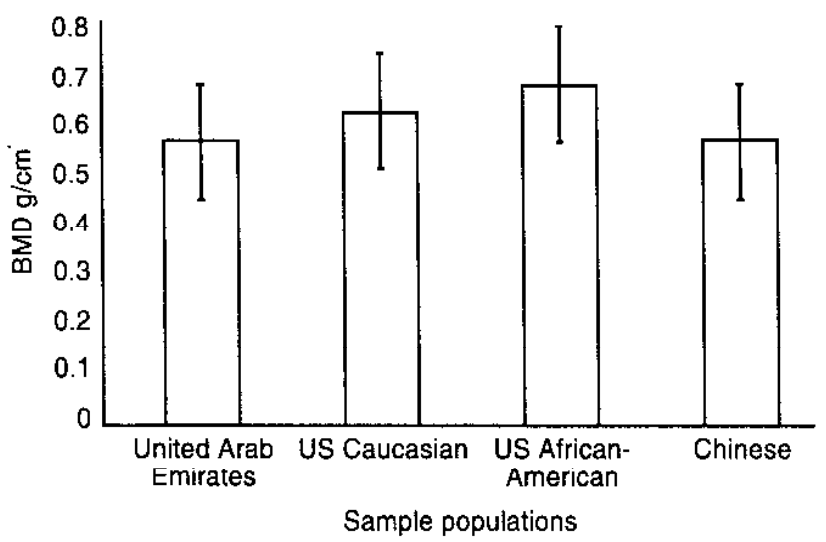

Figure 2 Estimated mean bone mineral density (BMD) of the heel in young women from different populations: Source: [18]

nia. These results are consistent with other studies in premenopausal women $[19-2 I]$. Although mean calcium intake was close to the recommended daily allowance for this age group, it is a cause for concern that a significant proportion of the participants consumed less than $500 \mathrm{mg} /$ day. Increased dietary calcium intake is associated with increased bone mass $[16]$ and reduced risk of hip fracture later in life $[14,15]$.

Finally, as shown in this and in other studies, the normative data supplied by manufacturers may over- or underestimate the proportion of a tested population categorized as having osteopenia or osteoporosis [22,23]. Thus, the construction of reference ranges that accurately represent the local population is essential for the correct identification of osteoporosis from BMD measurement [24]. Although the young adult BMD values determined in our study could be used as a reference database, one should have about 100-200 subjects in each age decade from 20 years to 80 years if detailed comparisons are to be slado $[25]$.
Some limitations of this study deserve comment. We measured bone density at a peripheral site by a relatively new technique [26]. Although T-score thresholds for subject classification are site- and techniquedependent [27], device-specific T-score thresholds are being constructed by international bodies [28], and the young adult reference values determined in this study could provide the basis for accurate implementation of the revised thresholds for SAHARA ultrasound in the UAE. In the small subgroup of participants studied, the correlation coefficient between heel BMD measured by SAHARA ultrasound and hip BMD measured by Lunar DXA was significant $(r$ $=0.7, P<0.05$ ) and representative of previously published results [29]. A second concern is that we studied mainly college and university students whose lifestyle may be quite different from the rest of the population. The vast majority of young women in the UAE, however, goes to college or university [30]. Therefore, studying mainly college and university students was appro- 
priate in order to obtain a representative sample of women in this age group.

In conclusion, local reference data are essential for the correct identification of osteoporosis from BMD measurements. Normal timing of onset of puberty and BMI are important determinants of bone density in young healthy UAE women. Mean BMD of UAE women is slightly lower than United States Caucasian women and Chinese women, although these differences are not statistically significant. Strategies need to be developed to encourage modification of all risk factors for osteoporosis early in life. This will allow individuals to achieve their full genetic potential for acquiring skeletal mass and consequently lower their future risk of fractures.

\section{Acknowledgements}

We thank Mrs Maha Chaltaf, Ms Saggira Al Falahi and Mr John Cherian, Faculty of Medicine and Health Sciences, United Arab Emirates Universicy for their technical assistance, and Dr Fric von Stetten, Hologic Incorporated, United States of America for providing reference data and for his critical review of the manuscript.

\section{References}

1. Hui SI, Slemenda CW, Johnston Jr CC. The contribution of bone lose to post menopausal osteoporosis. Osteoporosis international, 1990, 1:30-4.

2. Nordin BE, Polley KJ. Metabolic consequences of the menopause. A cross-sectional, longitudinal, and intervention study on 557 normal postmenopausal women. Calcified tissue international, 1987, 41(suppl, 1):S1-59.

3. Seeman $E$ et al. Reduced bone mass in daughters of women with osteoporosis. New England journal of medicine, 1989 , 320.554-8.

4. Slemenda CW et al. Genetic determinants of bone mass in adult women: a reovaluation of the twin model and the potential importance of gene interaction on heritability estimates. Journal of bone and mineral research. 1991. 6:561-7.

5. Rizzoli R, Bonjour JP. Determinants of peak bone mass and mechanisms of bone lose. Ostooporosis intornational, 1999, 9(suppl. 2):S17-23.

6. Pollitzer WS, Anderson JJ. Ethnic and genetic dilferences is bone mass: a re- view with a hereditary vs. environmental perepective. American journal of clinical nutrition, 1989, 50:1244-59.

7. Bonjour JP et al. Peak bone mass. Osteoporosis iniernat/onal, 1994, 4(suppl. 1):\$7-13.

8. Rizzoli $\mathbf{R}$ et al. Protein intake during childhood and adolescence and attainment of peak bone mass. In: Bonjour JP, Tsang RC, eds. Nutrition and bone development. Philadelphla, LIppincottRaven, 1999:231-43 (Nestle nutrition workshop series, Vol. 41).

9. Bonjour JP, Rizzoli R. Bone acquisition in adolescence. In: Marcus $R$, Feldman D, Kelsey J, eds. Osteoporosis. San Diego, Acadentic Press, 1990:405-70.

10. Armamento-Villareal $R$ et al. Estrogen status and heredity are major determinants of premenopausal bone mass. Journal of clinical investigations, 1992 , 90(6):2464-71.

11. Dhuper $S$ et al. Effects of hormonal status on bone density in adolescent girls. Journal of clinical endocrinology and metabolism, 1990, /1(5):1083-8. 
12. Ruiz JC, Mandel $C$, Garabedian M. Influence of spontaneous calcium intake and physical exercise on the vertebral and femoral bone mineral density of children and adolescents. Journal of bone and mineral research, 1995, 10(5):675-82.

13. Bass $S$ et al. Exercise before puberty may confer residual benefits in bone density in adulthood: studies in active prepubertal and retired female gymnasts. Joumal of bone and mineral research, $1998,13.500-7$

14. Matkovic $V$ et al. Bone status and fracture rates in two regions of Yugoslavia. American journal of clinical nutrition, $1979,32: 540-9$.

15. Halioua L, Anderson JJ. Lifetime calcium intake and pnysical activity nabits: Independent and combined effects on the radial bone of healthy premenopausal Caucasian womon. Amorican journal of clinical nutrition, 1989, 49:534-41.

16. Recker RR et al. Bone gain in young adult women. Journal of the American Medical Association, 1992, 268:2403-8.

17. Musaiger AO. Nutrition elements of food contents. Abu Dhabi, United Arab Emirates University Press, 1995.

18. International reference data quide. Bedford, MA, Hologic Incorporated, 1998 (080-0679 Rev C).

19. Ito $M$ et al. Relation of early menarche to high bone mineral density. Calcified tissue international, 1995, 57(1):11-4.

20. Young $D$ et al. Determinants of bone mass in 10- to 26-year-old females: a twin study. Journal of bone and mineral research. 1995, 10(4):558-67.

21. Kardinaal AF et al. Determinants of bone mass and bone geometry in adolescents and young adult women. Calcified tiosuo international, 2000, 66(2):81-9.

22. Petley GW et al. Reference ranges of bone mineral density for women in southern England: the impact of local data on the diagnosis of osteoporosis. British journal of radiology, 1996 , 69(823):655-60.

23. Ahmed Al et al. Screening for osteopenia and osteoporosis: do the accepted normal ranges lead to overdiagnosis? Osteoporosis international, $1997,7(5)$ : $432-8$.

24. Kanis JA et al. Guidelines for diagnosis and management of osteoporosis. The European Foundation tor Osieoporosis and Bone Disease. Osteoporosis international, 1997, 7:390-406.

25. Blake GM, Fogelman I. Applications of bone densitometry for osteoporosis. Endocrinology and metabolism clinics of Norn America, 1998, 27:267-88.

26. Baran DT. Quantitative ultrasound: a technique to target women with low bone mass for preventive therapy. American journal of medicine, 1995 , 98:48S-51S.

27. Faulkner $K G$, von Stetten E, Miller P. Discordance in patient classification using T-scores. Journal of clinical densitom. etry, 1999, 2(3):343-50.

28. Osteoporosis Prevention, Diagnosis and Therapy. NIH Consensus State. ment, 2000, 17(1):1-34 (http://conse nsus.nih.gov/cons/111/111_state ment. htm).

29. Graafmans WC et al. Ultrasound measurements in the calcaneus: precision and its relation with bone mineral density of the heel, hip, and lumbar spine. Bone, 1996, 19(2):97-100.

30. Al-Awais A. Al-Suwaidi K. Amiri N. Use of existing data for public health planning: a study of the prevalence of hepatitis $B$ surface antigen and core antibody in AlAin medical district, United Arab Emirates. Bulletin of the World Health Organization, 2000, 78(11):1324-9. 